\title{
Study of plasma frequency for Al-In alloys with different concentrations
}

\author{
${ }^{1,2}$ Zheng Yu, ${ }^{2}$ Beloshenko K. S., ${ }^{2}$ Makarovskiy M., ${ }^{2}$ Guliyova Y., \\ ${ }^{2}$ Shulga S., ${ }^{3}$ Wojnarowska R., ${ }^{3}$ Sheregii E. M. and ${ }^{3}$ Prokhorenko S. \\ ${ }^{1}$ Qingdao University, 308 Ningxia Road, Qingdao, Shangdong, 266071, China \\ ${ }^{2}$ Faculty of Radio Physics, Biomedical Electronics and Computer Systems, V. N. \\ Karazin Kharkiv National University, Kharkiv, Ukraine \\ ${ }^{3}$ Center for Microelectronics and Nanotechnology, University of Rzeszow, Poland
}

Received: 10.08 .2017

After revision: 21.09.2017

\begin{abstract}
In this work we report on spectrophotometric studies for two-layer granular films of Al-In alloys. The films are prepared using thermal precipitation in vacuum on roughened $\mathrm{NaCl}$ substrates heated to $300^{\circ} \mathrm{C}$, with subsequent deposition of additional layer of a NaCl-substrate material. As a result, the two-layer granular films of the alloys are immured in the substrate material. The films reveal two bands of plasma optical absorption, low- and high-frequency ones. The results obtained are interpreted using a modified Hampe-Shklyarevsky theory.
\end{abstract}

Keywords: Al-In nanoparticles, dipole-dipole interactions, nanostructures, absorption bands of optical films, plasma frequency

PACS: 42.25.Fx, 42.70.Ce, 61.46.-w, 71.55.Ak

UDC: 535.421

\section{Introduction}

A phenomenon of resonance absorption of light by granular films made of metals has been explored for more than half a century. Island metals influence mainly the positions of optical absorption bands. Hypothetically, if one deals with granular films of alloys comprised of different metals, the absorption band position depends on their relative amounts in the film. In this respect, it would be interesting to study plasma resonance in the granular films of Al-In alloys.

Consisting of granules isolated from each other, dispersed films of noble metals occupy a special place among different thin-film coatings. A transition from a continuous thin layer to a granular film is accompanied by appearance of absorption bands in the visible spectral region, which are otherwise absent in the spectrum of a bulk metal. The 'anomalous absorption bands' available in the granular films of noble metals can be explained with the aid of a modified HampeShklyarevsky theory (see Ref. [1]). If light falls on a film consisting of spherical metal granules isolated from each other, plasma oscillations of free electrons about a fixed centre of gravity of positive ionic charges are excited in the granules. This gives rise to a quasi-elastic force, which keeps electron gas near the equilibrium position. Here it is assumed that the granules with spherical radii $a_{0}$ are located at the nodes of a square grid with the side size equal to $a$. According to a modified Hampe theory, the equation of motion of free electrons in a metal is as follows [1]:

$$
\ddot{x}+\gamma \dot{x}+\omega_{0}^{2} x=k \frac{e}{m} E_{0} e^{i \omega t},
$$

where $x$ denotes the distance between the positive and negative charges (in our case this coordinate 
is a function of time), $e$ and $m$ are respectively the electron charge and mass, $E_{0} e^{i \omega t}$ is the electric field acting upon the granule-dipole, $\gamma$ the damping coefficient, and $\omega_{0}$ the eigenfrequency of free-electron oscillations occurring in spherical granules. The notation $k$ implies $k=3 \varepsilon_{0} /\left(\varepsilon_{1 m}+2 \varepsilon_{0}\right)$, with $\varepsilon_{0}$ and $\varepsilon_{1 m}$ being respectively the dielectric constant of environment and the interbound interaction. Note that, in case of the granular films, the field $E_{0} e^{i \omega t}$ acting on the electron in each granule should be replaced by

$$
E e^{i \omega t}=k E_{0} e^{i \omega t}+\frac{P}{\bar{\varepsilon} a^{3}}=k E_{0} e^{i \omega t}+\frac{4 \pi N e^{2}}{3 m \bar{\varepsilon}}\left(\frac{a_{0}}{a}\right)^{3} S,
$$

where $S$ and $q$ are respectively the duty factor and the filling factor, and $\bar{\varepsilon}=q \varepsilon_{m}+(1-q) \varepsilon_{0}$.

The dipole moment $P$ of the granule entering Eq. (2) is defined by the formula,

$$
P=\frac{4}{3} \pi a_{0}^{3} N e x
$$

where $N$ is the electron concentration. As a consequence, one can obtain the relations (see Ref. [1])

$$
\begin{aligned}
& \omega_{S}^{2}=\frac{\omega_{P}^{2}}{\varepsilon_{1 m}+2 \varepsilon_{0}}-\frac{\omega_{P}^{2}}{3 \bar{\varepsilon}}\left(\frac{a_{0}}{a}\right)^{3} S=\omega_{0}^{2}-\omega^{\prime 2}, \\
& \omega_{P}=\sqrt{4 \pi N e^{2} / m} .
\end{aligned}
$$

Here $\omega_{S}$ is the resonance frequency, $\omega_{P}$ the plasma frequency, $\omega^{\prime}$ the frequency parameter dependent on the influence of electric field of the remaining granule-dipoles upon a given granule, and

$$
\omega_{0}^{2}=\omega_{P}^{2} /\left(\varepsilon_{1 m}+2 \varepsilon_{0}\right)
$$

denotes the eigenfrequency of electron oscillations in the granule. It follows from the basic relationship of the modified Hampe theory given by Eq. (4) that the resonant frequency $\omega_{S}$ depends on the material of granule $\left(\varepsilon_{1 m}, N\right)$, its size $a_{0}$, the average distance $a$ between the granules, and the dielectric constant $\varepsilon_{0}$ of the environment that surrounds the granule. As seen from the above formulae, the resonance frequency $\omega_{S}$ is mainly determined by the plasma frequency $\omega_{P}$. The latter depends significantly on the concentration of free electrons in the metal granules. It is just this phenomenon that has been defined in Ref. [1] as a plasma resonance.

In experiments, the absorption spectrum of granular films is studied and the resonant frequency $\omega_{S}$ is found as a frequency $\omega_{S}^{\max }$ that determines the position of the absorption-band maximum. Both the first and second summands in Eq. (4) are functions of the frequencydependent parameters $\varepsilon_{1 m}$ and $\varepsilon_{0}$. The first summand, $\varepsilon_{1 m}$, is conditioned by the interband transitions and represents a parameter characteristic for a given metal. The second one, $\varepsilon_{0}$, can be changed within some limits via depositing insulators on granular films.

The results of optical and electron-microscopic studies of granular indium and aluminum films deposited on rough surfaces of $\mathrm{NaCl}$ and $\mathrm{KCl}$ single crystals have been reported in Refs. [2, 3]. After having performed spectrophotometric measurements, the authors of Ref. [4] have applied in vacuum an additional layer of $\mathrm{NaCl}$ or $\mathrm{KCl}$ to the original granular films, which is appropriate to the substrate material. Then the optical transmission $T=T(\lambda)$ has been measured again [4]. The optical density dependences $D=D(\omega)$ have been derived from the experimental results for each of the samples. The authors Ref. [2] believe that simultaneous excitation of the low-frequency bands 
for the indium-based granular films with the frequency $\omega_{S}$ and of the high-frequency bands with the frequency $\omega_{0}$ of natural electron oscillations in the isolated granules is possible only if the granules corresponding to the both bands do not belong to the same layer of the film. The latter is possible if the granular films deposited on the rough surface form a double layer (see Fig. 1). Some of the granules penetrated among the ridges of the rough surface form the lower layer of granules, which is surrounded by the corresponding insulator. The other are granulated on the surface of the rough substrate, thus forming an upper layer of the granules. Then the layers are isolated from each other. The natural electron vibrations with the frequency $\omega_{0}$ are excited in these indium granules.

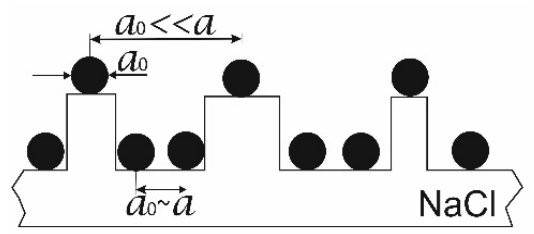

Fig. 1. Two-layer model of optical films deposited on a $\mathrm{NaCl}$ substrate. Higher-level granules have no dipole-dipole interactions.

As noted in the study [5], indium has no interband absorption in the spectral range $\hbar \omega=2.26 \div 11 \mathrm{eV}$. Then the expression for the natural frequency of electrons in the granules can be simplified, being dependent only on the plasma frequency $\omega_{P}$ and the dielectric constant $\varepsilon_{0}$ of the insulator surrounding the granules. If the parameters $\omega_{0}$ and $\varepsilon_{0}$ are known, one can calculate the plasma frequency $\omega_{P}$ entering Eq. (6). We obtain $\omega_{P}=17.46 \times 10^{15} \mathrm{~s}^{-1}$ for the indium granules embedded in sodium chloride, for which the frequency of the natural electron oscillations is equal to $\omega_{0}=6.95 \times 10^{15} \mathrm{~s}^{-1}$ and the dielectric constant to $\varepsilon_{0}=2.65$. This agrees perfectly with the data obtained in the study [2]. Notice that similar results have been obtained in Ref. [3] for the doublelayer films of aluminium granules embedded in the material of $\mathrm{NaCl}$ and $\mathrm{KCl}$ substrates. It has been found that the plasma frequency for aluminium amounts to $\omega_{P}=22.0 \times 10^{15} \mathrm{~s}^{-1}$. To some extent, this value correlates with the data reported by the other authors.

The authors of the study [6] have concentrated on the spectral dependences of optical density for the granular films of $\mathrm{Au}-\mathrm{Al}$ alloys. Pure $\mathrm{Al}$ deposited on fused-quartz substrates has also been investigated. The optical densities $D=D(\omega)$ for the granular films of the $\mathrm{Au}-\mathrm{Al}$ alloys of different concentrations reveal a common feature. This is a clearly visualized band of resonance absorption, which is characteristic of the resonant plasma absorption phenomenon. Then each sample (i.e., each band) corresponds to each alloy concentration. For the alloys with increasing aluminium concentration, the maximum of the plasma resonance band shifts towards high-frequency region, i.e. towards the resonant frequency of pure aluminium. Thus, one can assume that, during formation of the granular film heated up to $300^{\circ} \mathrm{C}$ on a substrate, granules of the $\mathrm{Au}-\mathrm{AI}$ alloys are formed.

Similar results were obtained in work [7] in experiments with two-layered granular films of $30 \% \mathrm{Al}-70 \%$ In alloy immured in a $\mathrm{NaCl}$ substrate material. During the experiments, two bands of plasma resonance were detected. The same bands were detected while takings measurements on two control samples with two-layer films of pure aluminum and pure indium, respectively.

The aim of the present work is to study experimentally the main features of plasma resonance in the two-layer granular films of Al-In alloys immured in the material of $\mathrm{NaCl}$ substrate. The primary object is dependence of the effect on the alloy concentration. In particular, we have been 
able to determine the plasma frequency $\omega_{P}$ governed by the nature of metal in the granules. To solve our problems, we have studied the resonant optical absorption for the two-layer granular films made of $\mathrm{Al}$ and $\mathrm{In}$, as well as their alloys immured in the material that forms the $\mathrm{NaCl}$ substrate.

\section{Preparation and characterization of specimen}

We have chosen $\mathrm{NaCl}$ single crystal as a substrate, first of all, due to the fact that it is practically transparent in a wide spectral range, $200 \div 800 \mathrm{~nm}$. Second, the very technique developed for obtaining double-layer granular films immured in a substrate material has been repeatedly tested just on the $\mathrm{NaCl}$ crystals. Our choice of metals is reasoned by the fact that $\mathrm{Al}$ and In have practically no interband absorption in the frequency region under test. The physical properties of the Al-In alloys have not been studied in a sufficient detail. Basing upon the state diagram of Al-In alloy, the solubilities of indium in aluminium in their solid states are negligible $(0.11 \%$ at $636^{\circ} \mathrm{C}$ - see Ref. [7]). The solubility of aluminium in liquid indium is equal to $39 \%$ at $875^{\circ} \mathrm{C}$, while the solubility of aluminium in solid indium is $2 \div 3 \%$ at $636^{\circ} \mathrm{C}$.

The samples were prepared as follows. Rectangular substrates with the sizes $4.5 \times 2.0 \times 0.5 \mathrm{~cm}^{3}$ were cut from a massive $\mathrm{NaCl}$ single crystal. Some of them were cut at the angle $10 \pm 1$ deg with respect to the surface and polished in a solution of isoamyl alcohol with distilled water (the ratio 1:7). The quality of grinding was checked under optical microscope. After grinding, the substrate was annealed in an oven at $650 \pm 5^{\circ} \mathrm{C}$ for $4 \mathrm{~h}$. As a result of annealing, the surface of the substrate became roughened and a step-like relief appeared. The presence of the steps was also checked using optical microscopy. While making the samples, a granular metal film was applied on a rough step-like surface of the $\mathrm{NaCl}$ substrate. There was a specially prepared stove above the substrate, which allowed heating the substrate up to $300^{\circ} \mathrm{C}$. The temperature was controlled with a thermocouple pressed against the substrate from the side to which the film was applied.

To obtain the alloy films in a given range of thicknesses and concentrations, experimentally determined weight quantities of $\mathrm{Al}$ and In were taken. Granular metal films in all the samples were placed in a vacuum unit VUP-5 in the vacuum as high as $5 \times 10^{5} \mathrm{~mm} \mathrm{Hg}$. Evaporation of the metals under study was carried out from molybdenum boats placed $15 \mathrm{~cm}$ away from the substrate, at the substrate temperature $300^{\circ} \mathrm{C}$. In the process of vacuum deposition of metals on the substrate, half of the latter was covered with a screen, so that it could be used as a reference model in subsequent spectrophotometric measurements.

The main dimensions of our optical films amounted to $a_{0} \sim 1 \div 5 \mathrm{~nm}$ and the distances between the granules were $a \sim 1 \div 10 \mathrm{~nm}$. After spattering of the granular film, a thin additional layer of $\mathrm{NaCl}$-substrate material, with the thickness up to $50 \mathrm{~nm}$, was applied to the working surface of the samples in the vacuum unit VUP-5 (the vacuum $5 \times 10^{-5} \mathrm{~mm} \mathrm{Hg}$ ). This additional $\mathrm{NaCl}$ layer was applied to ensure that the both layers of the granules were immersed in $\mathrm{NaCl}$. Such a technique made it possible to obtain double-layer samples (see Ref. [8]).

We prepared the alloy samples labelled as $\left(10_{\mathrm{Al}}-90_{\mathrm{In}}\right)$ (with $0.5 \mathrm{mg}$ of A1 and $4.5 \mathrm{mg}$ of In), $\left(20_{\mathrm{Al}}-80_{\mathrm{In}}\right)$ (containing $1.0 \mathrm{mg}$ of $\mathrm{A} 1$ and $4.0 \mathrm{mg}$ of In) and $\left(25_{\mathrm{Al}}-75_{\mathrm{In}}\right)$ (containing $1.25 \mathrm{mg}$ of $\mathrm{A} 1$ and $3.75 \mathrm{mg}$ of In). Finally, we used indium and aluminium samples with the weight $5 \mathrm{mg}$ as control samples of pure metals.

\section{Optical properties}

Spectrophotometric measurements on our samples have been conducted, using a spectrophotometer SF-26. It enables measuring spectral transmittances in the wavelength region 
$220 \div 1000 \mathrm{~nm}$. To interpret our results, we have used the modified theory of plasma resonance. One can assume that the two absorption bands observed experimentally are conditioned by the upper and lower layers of the two-layer granules (see Eq. (4)). In this case, some of the granules that penetrated in between the protuberances of the rough surface, form the lower layer of granules surrounded by $\mathrm{NaCl}$. These closely spaced granules are responsible for appearance of the lowfrequency band. The granules of the second portion are placed on the tops of relief elements. These granules are far enough from each other to ensure neglecting their dipole-dipole interactions. Inside these isolated granules, the natural oscillations of electrons are excited, which are responsible for the second (high-frequency) band. It is obvious that the maximum of the lowfrequency band is defined by the resonance frequency $\omega_{S}$ (see Eq. (4)). The maximum of the highfrequency band is given by the natural frequency $\omega_{0}$, as shown in Eq. (6).

Since the both layers of the metal granules in our samples are embedded in $\mathrm{NaCl}$, interpretation of the experimental results becomes simpler. To explain our data obtained for the granular films of Al-In alloys (see Fig. 2), one can suppose that homogeneous compositions of the alloy are formed in the process of film formation on a rough substrate heated to $300^{\circ} \mathrm{C}$. Two plasma resonance bands are clearly visible in Fig. 2. However, only high-frequency bands, of which maximum positions are determined by $\omega_{\max 2}$, are of interest when making accurate estimates. These parameters are different for the alloys of different concentrations.

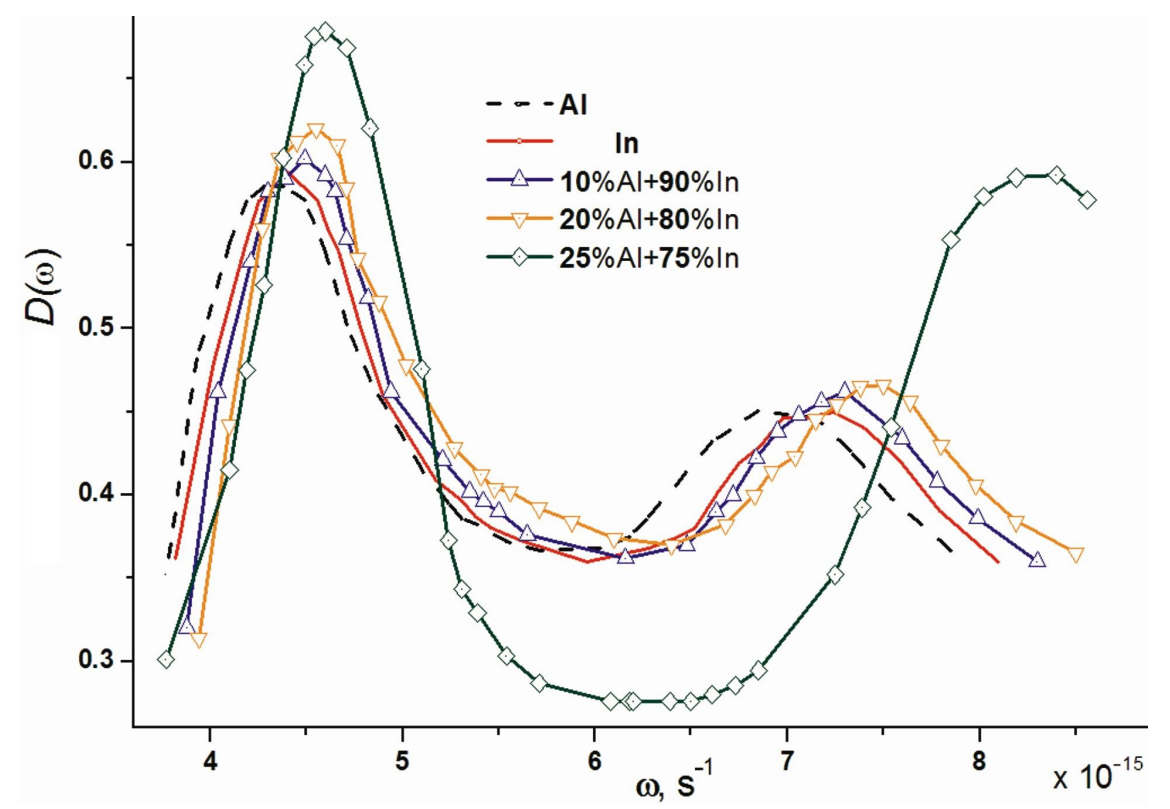

Fig. 2. Spectral optical densities measured for the granular films deposited on $\mathrm{NaCl}$ substrates.

One can find the $\omega_{p}$ values from the positions of maxima of the high-frequency bands derived for the granules of the alloys of different concentrations. This may be done when assuming that $\omega_{0}=\omega_{\max 2}$ and using Eq. (5), from which the relation $\omega_{p}=\omega_{\max 2} \sqrt{\varepsilon_{1 \mathrm{~m}}+2 \varepsilon_{0}}$ follows. The values $\varepsilon_{0}$ for the appropriate frequencies $\omega_{\max 2}$ are known from Ref. [9]. Moreover, the $\varepsilon_{1 \mathrm{~m}}$ parameters for these metals in the frequency interval under study can be found, basing on the technique suggested in Ref. [10]. The main parameters calculated from the experimental results are gathered in Table 1.

Ukr. J. Phys. Opt. 2017, Volume 18, Issue 4 
Table 1. The main frequency parameters calculated from our experiments for the Al-In alloys of different concentrations.

\begin{tabular}{|c|c|c|c|c|}
\hline Alloy material & $\omega_{\max 1}, 10^{-15} \mathrm{~s}^{-1}$ & $\omega_{\max 2}, 10^{-15} \mathrm{~s}^{-1}$ & $\omega_{p}, 10^{-15} \mathrm{~s}^{-1}$ & $\omega_{p}^{\text {cal }}, 10^{-15} \mathrm{~s}^{-1}$ \\
\hline $\mathrm{Al}$ & 4.6 & 8.4 & 22.0 & - \\
\hline $\mathrm{In}$ & 4.38 & 6.95 & 17.5 & - \\
\hline $10 \% \mathrm{Al}+90 \% \mathrm{In}$ & 4.40 & 7.1 & 17.8 & 18.0 \\
\hline $20 \% \mathrm{Al}+80 \% \mathrm{In}$ & 4.49 & 7.3 & 18.4 & 18.4 \\
\hline $25 \% \mathrm{Al}+75 \% \mathrm{In}$ & 4.55 & 7.5 & 19.0 & 18.6 \\
\hline
\end{tabular}

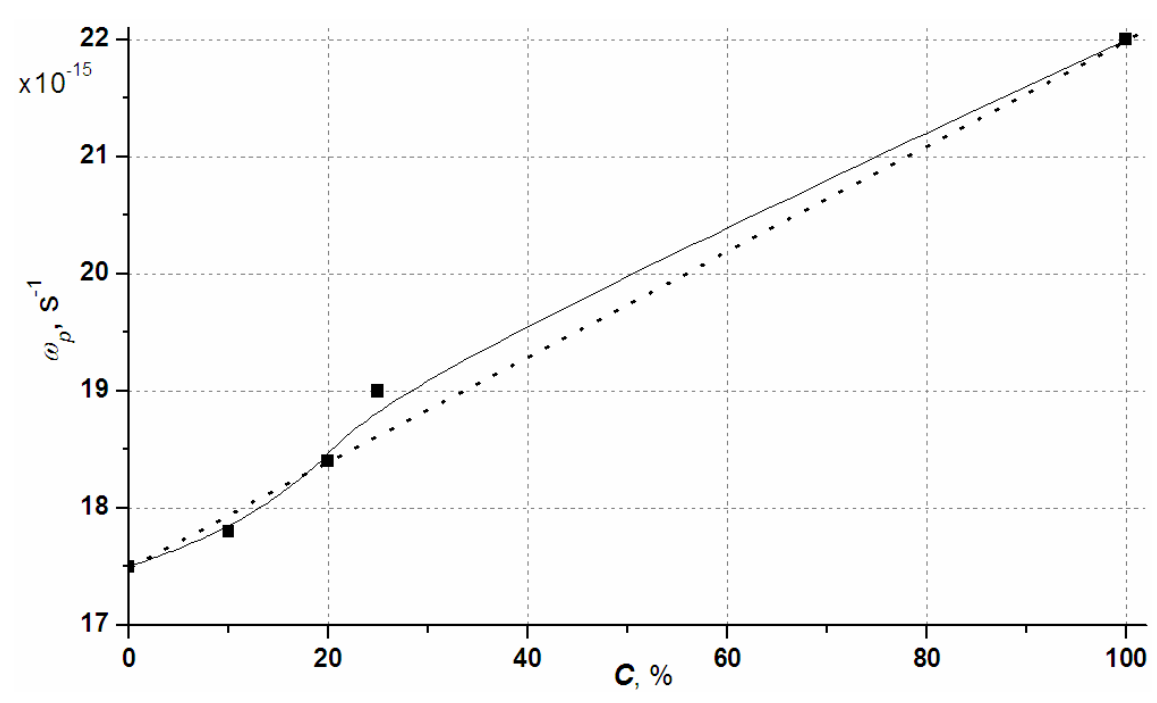

Fig. 3. Dependence of experimental plasma frequency for free electrons in the granules on the Al concentration (solid squares) and its theoretical fit (dot curve).

To check our results, one can assume that the $\omega_{p}$ values are determined by the relative concentrations of metals in the alloy (see Fig. 3). Then we obtain

$$
\omega_{P}^{\mathrm{AlIn}}=C^{\mathrm{Al}} \omega_{P}^{\mathrm{Al}}+C^{\mathrm{In}} \omega_{P}^{\mathrm{In}} .
$$

The results of the corresponding calculations are presented in Table 1 in the column $\omega_{P}^{c a l}$. The parameters obtained by us seem to be quite reasonable.

\section{Conclusion}

In this work we have studied the two-layer granular films of Al-In alloys with different metal concentrations, which are immured in the material of the $\mathrm{NaCl}$ substrate. The two bands of resonance optical absorption have been detected. It has been revealed that the positions of the high-frequency bands depend on the alloy concentration. Finally, we have estimated the corresponding $\omega_{P}^{\mathrm{AlIn}}$ parameters.

\section{References}

1. Al-Abdella R B and Shklyarevskii I N, 1980. Plasma oscillations of electrons in granular indium films. J. Appl. Spectr. 33: 1124-1129.

2. Shklyarevskii I N, Bondarenko $\mathrm{Yu} \mathrm{Yu}$ and Makorovskii N A, 2000. Natural electron oscillations in granular indium films deposited on rough surfaces of $\mathrm{NaCl}$ and $\mathrm{KCl}$ single crystals. Opt. Spectr. 88: 542-546. 
3. Shklyarevskii I N, Bondarenko Yu Yu and Makorovskii N A, 1999. Natural electron oscillations in granular aluminum films deposited on rough surfaces of $\mathrm{NaCl}$ and $\mathrm{KCl}$ single crystals. J. Appl. Spectr. 66: 999-1003.

4. Shklyarevskii I, Pakhmov P and Korneeva T, 1973. Plasma resonance in granular silver and gold films. Opt. Spektrosk. 34: 729-736.

5. Sánchez-Royo J F, Muñoz-Matutano G, Brotons-Gisbert M, Martínez-Pastor J P, Segura A, Cantarero A, Mata R, Canet-Ferrer J, Tobias G, Canadell E, Marqués-Hueso J and Gerardot B D, 2014. Electronic structure, optical properties, and lattice dynamics in atomically thin indium selenide flakes. Nano Res. 7: 1556-1568.

6. Makarovsky N A and Letyago L M, 2006. Plasma resonance in granular films of Au-Al system alloys. Visn. Kharkiv. Univ., Ser. Fiz. 739: 138-140.

7. Okamoto H. Phase diagrams for binary alloys: desk handbook ( $2^{\text {nd }}$ Ed.) Materials Park: ASM International, 2010.

8. Shklyarevskii I N, Bondarenko Yu Yu and Makarovskii N A, 2000. Plasma resonance in granular gallium films deposited on rough $\mathrm{NACl}$ and $\mathrm{KCl}$ single-crystal surfaces. Opt. Spectr. 88: 547-550.

9. Wolfe $\mathrm{W}$ L and Zissis G J. The infrared handbook ( $4^{\text {th }}$ Printing). Michigan: ERIM, Ann Arbor, 1993.

10. Kreibig U and Vollmer M. Optical properties of metal clusters, Vol. 25. Berlin-Heidelberg: Springer Science\& Business Media, 2013.

Zheng Yu, Beloshenko K. S., Makarovskiy M., Guliyova Y., Shulga S., Wojnarowska R., Sheregii E. M. and Prokhorenko S. 2017. Study of plasma frequency for Al-In alloys with different concentrations. Ukr.J.Phys.Opt. 18: 225 - 231.

\begin{abstract}
Анотація. У иіий праці представлено спектрофотометричні дослідження двошарових гранульованих плівок Al-In сплавів. Плівки підготовлено за допомогою термічного осадження у вакуумі на шорстких підкладках $\mathrm{NaCl}$, нагрітих до $300^{\circ} \mathrm{C}$, із подальшим висадженням додаткового шару матеріалу підкладки $\mathrm{NaCl}$. Як результат, двошарові гранульовані плівки сплавів виявляються зануреними в матеріал підкладки. Плівки виявляють дві смуги оптичного плазменного поглинання - низькочастотну та високочастотну. Результати проінтерпретовано в рамках модифікованої теорії ХампеШкляревського.
\end{abstract}

